\title{
Menyikapi Globalisasi Pendidikan Tinggi
}

\author{
Jaka Winarno A.
}

The liberalization of the higher education tends to open the access for the investors or the big capital owners of education force their interest and ther needs to higher education and its human resources. Thus, higher education can put beside in searching for the truth and humanize human that become the function of fundamental education because of the industries interest who give funding. The entering of free market, corporate culture and industries will influence the mission of higher education. Ethics and moral of higher education is occupied by ethics and moral of business based on looking profit and efficiency.

Kata Kunci: perguruan tinggi,pasar, globalisasi, kepentingan.

$\mathrm{M}$ unculnya istilah liberalisasi pendidikan tinggi dalam konteks ini bermula dari WTO yang menganggap pendidikan tinggi sebagai jasa yang bisa diperdagangkan atau diperjualbelikan, sebagai catatan, pemerintah Republik Indonesia telah meratifikasi WTO melalui UU No. 7/1994. Dengan demikian sejak saat itu Indonesia menjadi salah satu anggota WTO yang memiliki kewajiban untuk menaati segala aturan main yang ada di dalamnya. Organisasi WTO dalam mengatur sistem perdagangan intemasional mem-bedakannya dalam dua kategori, yaitu kategoriperdagangan barang dan perdagangan jasa. Mekanisme perdagangan barang diatur dalam GATT (GeneralAgreement on Tariff and Trade), sedangkan perdagangan jasa diatur dalam GATS (General Agreement on Trade in Services) (Supriyoko dalam Freelists).

Sampai saat ini WTO telah membagi belasan sektor jasa yang dapat diperdagangkan di tingkat dunia. Adapun satu dari belasan sektor tersebut adalah jasa pendidikan. Karena pendidikan dimasukkan dalam sektor jasa maka pendidikan menjadi sesuatu yang dijualbelikan. Jadi praktik perdagangan atau jual beli jasa pendidikan hukumnya sah dan dapat dipertanggungjawabkan menurut kacamata WTO.

Beberapa model perdagangan atau jual beli jasa pendidikan tinggi versi WTO dapat dijelaskan sebagai berikut: Pertama, disebut model cross Border Supply, dalam hal îni suatu lembaga pendidikan pada suatu negara menjual jasa pendidikan tanpa kehadiran fisik lembaga kepada konsumen yang berada di negara lain. Contoh, banyak orang-orang Indonesia yang mengikuti program pendidikan jarak jauh (distance learning) serta pendidikan maya (virtual education) yang diselenggarakan negara manca; misalnya United King-Dom Open University (Ingrris) dan Michigan Virtual University (AS).

Kedua, disebut model Consumption Abroad. Dalam hal ini lembaga pendidikan suatu negara menjual jasa pendidikan dengan menghadirkan konsumen dari negara lain. Contohnya saat ini terdapat ribuan pemuda Indonesia yang belajar pada perguruan tinggi ternama diAustralia, seperti Monash University, Melbourne University, 
UNSW, dsb. Dalam hal ini kita menjadi pembeli jasa pendidikan yang dijual oleh Australia dengan cara hadir di Australia. Ketiga, disebut model Movement of Natural Persons. Dalam hal ini lembaga pendidikan di suatu negara menjual jasa pendidikan ke konsumen di negara lain dengan cara mengirimkan personelnya ke negara konsumen. Contohnya, banyak perguruan tinggi kita seperti UI Jakarta, UGM Yogyakarta, dan beberapa PTS yang ternama mempekerjakan dosen dari AS, Australia, Jepang, Jerman, inggris, dsb. Sebaliknya ada bebrapa perguruan tinggi di negara manca seperti Monash University di Australia dan National University of Singapore (NUS) di Singapura telah mempekerjakan dosen yang berasal dari Indonesia. Keempat, disebut model Commercial Presence, yaitu penjualan jasa pendidikan oleh lembaga di suatu negara bagi konsumen yang berada di negara lain dengan mewajibkan kehadiran secara fisik lembaga penjual jasa dari negara tersebut. Hadirnya PTA dari negara manca untuk menjual jasa pendidikan tinggi kepada konsumen di Indonesia adalah contoh yang sangat tepat untuk model perdagangan jasa pendidikan ini. Terlepas dari sejauh mana penyelesaian masalah izin penyelenggaraan PTA oleh lembaga yang bersangkutan, dalam realitanya kehadiran PTA di Indonesia memang sudah terjadi.

\section{Misi Dasar Pendidikan}

Pendidikan mengemban misi penyadaran (conscientitation) atau istilah-istilah serupa lain, seperti pemerdekaan dan pemanusiaan. Ini misi dasar mulia. Pendidikan harus membuat orang kian sadar akan jati diridan asal-usul, dunia dan lingkungan alam sosial, serta tanggungjawabnya. Pendek kata, pendidikan dimaksudkan membawa orang pada kesadaran insani. Dalam konteks ini, kemampuan memilih dikedepankan. Artinya, apa keputusan sikap seseorang dalam kaitan dengan kesadaran jati diri dan lain-lain, asal dipilih sendiri secara sadar, adalah wujud keberhasilan pendidikan. Dalam bahasa Daoed Joesoef (Tantangan bagi Individu Otonom, Kompas 24-804), pendidikan harus mendorong individu menjadi lebih otonom, yang tidak berjwa bebek, mampu berfikir mandin, dan bertindaksendiri, berkat kekuatan nalar pribadi dan semangatnya yang kritis. Otonom untuk menentukan sikap dan tindakan atas dasar pertimbangan. Masalahnya, sejauh mana dapat dijamin (dan oleh siapa) bahwa pilihan sikap, perilaku, atau paham individu-individu otonom hasil proses pendidikan itu in favor dengan tujuan pendidikan yang telah dijalani, bagaimana jika oleh kesadaran yang tumbuh melalui proses pendidikan, orang lalu memilih untuk, misalnya, menjadi teroris? Seperti diketahui, mereka yang dicurigai telah melakukan aksi berbagai teror bom bukan orang-orang berpendidikan formal rendah.

\section{Ideologisasi}

Dibalik misi penyadaran yang diembannya, kita melihat ruang kosong praksis dunia pendidikan formal. Jika pendidikan memanusiakan, mengapa kian besar gejala deviasi tindakan mereka yang.terdidik? Gejala itusebagai kesenjangan kesadaran wacana dan kesadaran perbuatan. Kesenjangan ini harus dikikis dengan mengisi ruang kosong yang timbul dari misi penyadaran pendidikan. Ruang kosong itu adalah tidak adanya ideologisasi tujuan pendidikan. Artinya, tidak ada raison d'etreyang dipahamkan kepada peserta didik untukmenumbuhkan keyakinan, bahwa tujuan pendidikan hanus dicapai demi suatu ideal yang dianggap lebih tinggi dan luas. Ideologisasi menjadikan tujuan pendidikan sebagai semangat dasar proses. (Syafii Maarif dalam Dialog). 
Sejauh ini tujuan pendidikan kita ada karena tuntutan normatif sosial,dan tidak tumbuh bersemi dalam diri insan peserta didik, menjadi bagian tujuan hidupnya. Proses pendidikan kita tidak membuat peserta didik memahami ideal di balik tujuan pendidikan. Tujuan dicapai demi tujuan itu sendiri, sehingga kesediaan berkorban dalam perjuangan mendekati ideal amatlah kecil, karena yang terdidik tidak disatukan dengan tujuan pendidikan itu. Di sinilah letak pentingnya ideologisasi tujuan pendidikan. Tujuan pendidikan menjadi target sekaligus semangat praksis pendidikan. Pencapaiannya bersifat imperatif dan dilakukan dengan semacam driling tujuan, sebagai semangat ideologi yang harus diwujudkan. Ini perkara metodologi, agar praksis pendidikan tidak dipisahkan-tidak dialienasikan-dari tujuan pendidikan sendiri. Akan hainya substansi pendidikan, kita memilikinya secara amat berlimpah, baik yang eksplisit telah tersurat maupun yang mengendap dalam keutamaan-keutamaan masyarakat kita.

\section{Tantangan Ganda}

Sudah sering dibahas, dunia pendidikan dimasa kini menghadapi tantangan yang muncul dari proses pengglobalan masyarakat. Ini meliputi, misalnya, bagaimana "mengompromikan" visi humanistik dengan visi utilitarian pendidikan. Soal keberpihakan institusi-institusi pendidikan dalam aras polarisasi lapisan sosial ekonomi masyarakat, masih menjadi isu penting perdebatan pelaku pendidikan. Namun, dunia pendidikan masa kini juga menghadapi tantangan yang muncul dari gerakan kontra globalisasi, terutama atas dominasi sekelompok masyarakat dunia. Gerakan ini mengambil berbagai bentuk dan intensitas, tetapi kiranya terorbom memberi pesan paling jelas tantang misi gerakan yang fundamentalistik.
Dunia pendidikan ditantang adu strategi dan metode mengarahkan kesadaran individu atas pilihan-pilihan hidupnya. Adalah kegagalan dan ironi yang harus memancing refleksi jika mereka yang bertahun-tahun mengenyam pendidikan bervisi kemanusiaan, lalu memutuskan memilih menjadi pembunuh puluhan orang tak berdosa, hanya karena perjumpaan beberapa saat dengan yang tidak mencintai kemanusiaan. Oleh karena itu, pendidikan masa kini harus mampu menjawab sekaligus kedua tantangan yang muncul dari arus-arus globalisasi yang bertentangan itu. Penguasaan teknologi telah sering disebut sebagai salah satu jawaban atas tantangan globalisasi. Pemilihan strategi dan metode pendidikan merupakan jawaban atas tantangan gerakan kontra globalisasi. Jika gerakan kontra globalisasi mampu mengarahkan para lulusan sekolah bervisi kemanusiaan menjadi pembunuh dengan semangat militan, maka mungkin pada sisi menumbuhkan semangat militan, itulah sekolah bervisi kemanusiaan kita lemah. Karena itu, strategi dan metode pendidikan yang dapat menjawab tantangan gerakan kontra globalisasi adalah strategi dan metode pendidikan yang menumbuhkan militansi kemanusiaan. Pendidikan bervisi kemanusiaan harus membuat orang matimatian dalam sikap dan perilakunya berpihak pada nilai-nilai dan tujuan kemanusiaan. Ini dapat terwujud jika ada ideologisasi visi dan misi kemanusiaan dalam praksis pendidikan.

Globalisasi pendidikan sebenarnya tidak periu terlalu dikhawatirkan, tetapi harus disikapi dengan benar.Belum tentu lembaga pendidikan asing langsung membuka kelasnya di Indonesia bila globalisasi pendidikan diberlakukan. Perguruan tinggi asing yang benar-benar berkualitas masuk ke Indonesia justru akan menangguk rugi. Contoh di Malaysia biaya pendidikan 
mencapai Rp 60 juta. Kalau masuk ke Indonesia, adakah orang Indonesia yang mau menyekolahkan anaknya di Perguruan Tinggi itu bila harus membayar semahal itu? Jadi kalau perguruan tinggi asing yang berkualitas masuk ke Indonesia justru akan rugi. Hal ini, menurut Wardiman, berbeda dengan anak-anak orang kaya yang dikirim ke luar negeri untuk kuliah. Anak-anak ini datang ke perguruan tinggi negeri di luar negeri datang satu persatu dan tidak diorganisir sehingga perlakuannya beda bila sebuah perguruan tinggi dibuka di Indonesia.Untuk mendirikan sebuah perguruan tinggi paling tidak harus dibutuhkan mahasiswa sampai 400 orang. Hal tersebut bukan biaya yang murah, Wardiman Djojonegoro, dalam Forum Rektor mengatakan sebenarnya kalau yang dikhawatirkan adalah perguruan tinggi asing yang berkualitas masuk ke Indonesia, perguruan tinggi negeri Indonesia tidak akan kalah. Di UI misalnya, biaya pendidikan sekitar Rp 10 Juta, di Trisakti Rp 15 juta. Bagaimana halnya kalau Monash University yang buka cabang di Indonesia dengan SPP. Rp 60 juta. Universitas tersebut sudah pasti akan kekurangan mahasiswa. Wardiman justru lebih menekankan, kebijakan link and match yang pernah diterapkannya ketika masih menjadi menteri pendidikan dan kebudayaan. Kebijakan link and match berarti pendidikan tidak boleh berdiri sendiri tetapi harus bekerja sama dengan dunia kerja. Dengan demikian, lulusan dunia pendidikan bisa tertampung dalam dunia kerja.

Wardiman menambahkan, globalisasi itu adalah persaingan yang keras di mana dunia kerja berubah dengan cepat dan bersaing. Perguruan tinggi yang menghasilkan ribuan tenaga kerja harus siap dengan globalisasi, dengan memperhatikan prinsip link and match itu. Bagaimana perguruan tinggi bisa menyesuaikan kurikulumnya dengan kebutuhan globalisasi? Globalisasi itu adalah persaingan. Kalau insinyur perguruan tinggi Indonesia kualitasnya lebih rendah dari insinyur Malaysia, berarti kita kalah bersaing. Wardiman mengungkapkan pendidikan memiliki lima rantai, yaitu gedung, buku, kurikulum, guru, dan anggaran. Kelima komponen itu harus berjalan, saling terkait. Jadi pendidikan kita itu masih sangat tertinggal dibandingkan dengan negara lain.

Dengan demikian, dalam hal pembiayaan, bisa dipastikan pergunuan tinggi di Indonesia akan menang bersaing dengan perguruan tinggi asing yang akan dibuka di Indonesia bila globalisasi pendidikan diberlakukan. Sekolah pelita harapan, yang mematok biaya pendidikan lebihjauh dibanding sekolah-sekolahumumnya yangada di Indonesia, tidak sendirian.Banyak sekolah bertaraf internasional diminati masyarakat di Indonesia. Di sisi lain, tidak sedikit perguruan tinggi di Indonesia yang hanya sekedar papan nama semata. Banyak perguruan tinggi swasta di Bandung yang terancam gulung tikar karena kekurangan mahasiswa. Bukan hanya di Bandung, sejumlah perguruan tinggi negeri di daerah pun kekurangan anak didik karena berbagai faktor. Ada yang disebabkan kualitas pendidikan di PTS yang tidak memadai, ada pula yang disebabkan biaya pendidikan yang cukup mahal sehingga tidak memungkinkan anak-anak lulusan sekolah menengah melanjutkan pendidikan ke jenjang pendidikan yang lebih tinggi. Mengenai kualitas PTS yang belum memungkinkan untuk menghadapi globalisasi pendidikan, baiknya bercermin pada langkah yang dilakukan universitas di Inggris yang memilih melakukan merger demi mengejar kualitas lebih baik. Dua universitas ternama tersebut adalah University College London dan Imperial College. Dua 
perguruan tinggi itu dilakukan guna meningkatkan kualitas lulusannya. Seperti diketahui, Imperial College yang didirikan pada tahun 1907 sangat disegani dalam percaturan pendidikan internasional karena memiliki kredibilitas dibidang sain dan teknologi, sementara university College London yang lebih tua usianya berdiri tahun 1826 juga memiliki kredibilitas yang cukup tinggi.

Langkah merger demi meningkatkan kualitas lulusan itu tampaknya harus menjadi pelajaran berharga bagi perguruan tinggi di Indonesia. Bagaimana mungkin sebuah perguruan tinggi di Indonesia dapat berdiri tanpa mampu menjamin kualitas 'lulusannya. Tidak jarang sebuah perguruan tinggi memasang nama besar bergelar profesor, doktor, dan sebagainya, tetapi sekalipun nama-nama itu tidak pernah memberikan kuliahnya di perguruan tinggi itu. Belum lagi fasilitas-fasilitas lain yang sangat minim. Sebuah perguruan tinggi tanpa laboratorium, lembaga penelitian, dan lain sebagainya. Berkaca dari kondisi perguruan tinggi yang ada di indonesia seperti itu, tampaknya globalisasi pendidikan memang harus menjadi titik pijak bagi pelaku pendidikan di Indonesia untuk membenahi diri dan mulai menjadikan anak didik sebagai subyek dan bukan obyek untuk memperkaya diri. Bagaimanapun, sudah saatnya perguruan tinggi di Indonesia membenahi diri dalam rangka berkontribusi bagi peningkatan kualitas sumber daya manusia Indonesia.

\section{Efek Globalisasi Pendidikan (Inklusif)}

Globalisasi telah membawa efek ganda.Masing-masing komunitas dapat meningkat jumlahnya dan meluas pengaruhnya dan pada setiap negara. Jumlah komunitas iman dapat terus bertambah.Internet telah membuka sebuah panorama kesempatan bagi komunitaskomunitas iman untuk mempromosikan dan mempersembahkan keyakinannya. (Muhammad Ali, Kompas 29-3-06)

Proses migrasi dan komunikasi telah menimbulkan tanggapan-tanggapan yang kontradiktif, sebagian komunitas bersifat konfrontasional dengan memonopoli kebenaran dan akses terhadap keselamatan, sedangkan yang lain lebih adaptif, mencari jalan-jalan menuju rekonsiliasi iman melalui sain dan dinamika sekulerisme. Jika kita membuat sebuah garis lurus, titik paling kanan kita dapati komunitas-komunitas iman yang inklusif, titik paling kiri kita dapati komunitas-komunitas iman yang paling eksklusif.

Pertanyaannya, bagi pemimpin dan umat beragama di Indonesia khususnya, adalah bagaimana mereka mampu menghadapi tantangan globalisasi iman ini dengan bijak. Negara jelas tidak akan mampu lagi mengontrol lalu lintas informasi melalui internet. Kebijakan untuk mengakui beberapa agama saja hingga saat ini enam agama, termasuk Khong hu cu, pada kenyataannya tidak efektif, yang menguat dalam konteks ini justru civil society. Masyarakat sendiri yang paling pas dan berkuasa menentukan, memilih, menyaring informasi yang didapat dari internet. Bagi masyarakat menengah ke atas yang memiliki jaringan internet, tentu saja globalisasi iman ini begitu terasa. Sebagian mereka semakin merasakan manfaat globalisasi itu, misalnya bahwa pengetahuan mereka tentang agama-agama dan imaniman lain semakin bertambah. Sebagian lagi semakin defensif. Terlepas banyaknya informasi yang diperoleh, sebagian kelompok iman cenderung mempertahankan keyakinannya sendiri dan berusaha membela diri, ancaman pola pikir keberimanan yang lain, baik aktual maupun 
potensial. Dengan kata lain, globalisasi memiliki dua efek sekaligus: positif dan negatif.

Dalam konteks itu, untuk memahami perkembangan global di atas, bagaimana kita menyikapi globalisasi iman itu dalam konteks keberimanan kita masing-masing. Di sini pentingnya mempelajari sejarah agama-agama atau iman-iman. Mengapa? Dengan belajar agama-agama yang berbeda, kita dapat lebih tahu banyak tentang agama-agama dan lebih terdidik. Lebih jelasnya, kita telusuri manfaat belajar sejarah agama-agama sebagai akibat globalisasi.

Pertama-tama, kita bisa lebih paham terhadap tradisi agama-agama, setiap agama itu menerik karena merupakan sistem nilai yang kompleks, hubunganhubungan, kepribadian-kepribadian, dan kreativitas manusia. Kita tidak akan menggeneralisasi agama-agama lain, misalnya mengidentikkán sesuatu agama dengan kekerasan. Kita dapat lebih mengerti kesamaan agama-agama. Studi agamaagama memerlukan simpati dan obyektivitas. Seseorang dapat berlaku sebagai insider dan outsider sekaligus. Di situ akan ditemukan kesamaan iman dan praktik dalam banyak hal.

Selanjutnya, kita dapat lebih toleran. Karena setiap manusia memiliki perasaan, agama-agama yang diyakini dapat menimbulkan perasaan-peràsaan yang menggelora untuk mengatasi kesengsaraan bersama. Setiap sejarah telah membuktikan, komunitas-komunitas agama telah bergantung pada sensor dan otoritarianisme (eksekusi, diskriminasi, dan lain-lain) untuk memaksakan kehendak. Dengan belajar agama, kita dapat terbantu untuk lebih obyektif dan lebih toleran. Kita bisa lebih menghargai perbedaan-perbedaan, dalam dunia yang multikultural, penghargaan atas perbedaan-perbedaan adalah berharga, tetapi menikmati perbedaan-perbedaan itu lebih baik lagi. Keragaman adalah kenyataan alamiah, dan orang yang dapat menikmati keragaman dalam iman dan hal-hal lain tidak akan capek dalam hidup.

Kitajuga terbawa untukmelihat kehidupan sehari-hari, pengaruh-pengaruh keberagaman dapat ditemukan di mana-mana saja dalam budaya modem dan bahkan postmodem saat ini, tidak hanya di tempat-tempat ritual. Kehidupan, ekonomi, politik dan lain-lain, dipengaruhi keberimanan seseorang atau kelompoktertentu, baik yang formalistikmaupun yang substantifistik. Dengan belajar agamaagama, kita terbiasa menjalani kehidupán dengan keberagaman kita sendiri sambil memahami, dan mungkin pula, mengalami keberagaman yang lain. Lebih jauh, belajar agama-agama yang berbeda dapat membantu dalam pencarian iman sendiri. Tidak setiap orang menjadi artis atau budayawan, tetapi kita memilikj kemampuan untukmengapresiasikan seni, musik, atau sajak misalnya.

Begitu pula agama, meskipun sebagian orang tidakmenganutagamayanglain, mereka dapat memiliki kemampuan untuk merasakan sebagian atau sedikit dari keberagaman orang lain. Ada Insting keberagaman, ada rasa tentangyang suci. Cerita-cerita pencarian iman orang lain dapat membantu memperkaya pencarian iman kita sendiri. Oleh karena itu, pendidikan inklusif tampaknya perlu mendapat tempat. Jika tidak di sekolah-sekolah, paling tidak di pendidikan tinggi atau LSM-LSM. Perdebatan mengenai RUU SistemPendidikan Nasional yang lalu dan saat ini sudah disảhkan seharusnya tidak menelantarkán salah satu tugas penting kalangan pendidik, yaitu memberikan ruang kebebasan kepada anak didik atau mahasiswa untuk mendapatkan informasi mengenai pluralitas keberagamaan, disamping keberagamaan yang sudah dipeluk sebelumnya. 
Menyadari globalisasi sebagai tantangan dan melihat beberapa manfaat dari belajar keragaman agama-agama seperti diurai di atas, kiranya pendidikan inklusif, selain pendidikan agama yang dipeluk, perlu dikembangkan di dunia pendidikan di negeri kita; tentu saja dengan materi, metodologi, dan pengajar yang baik dan tepat,dan berpaham inklusif. Sebuah pekerjaan yang cukup berat dan menantang, tetapi dengan pendidikan inklusif, dapat lahir manusiamanusia yang sadar, cerdas, dan bijak dalam memahami realitas keragaman iman.

\section{Kiat Menghadapi Liberalisasi Pendidikan}

Untuk menyikapi terhadap liberalisasi pendidikan, pemerintah harus menyiapkan kebijakan-kebijakan yang cerdas, strategis, dan ânisisipatif, menghadapi gelombàng globalisasi yang juga akan menyentuh pendidikan tinggi. Dengan demikian, nilai-nilai positif dari arus globalisasi itu dapat ditepis dan sebaliknya menyerap nilai-nilai positifnya. Kalimat-kalimat di atas sebetulnya juga merupakan kesimpulan hasil seminar di Unikā Atma Jaya Jakarta tentang pendidikan tinggi di era pasar bebas. Gun Besar Universitas Negeri Jakrta (UNJ) HAR Tilaar mengatakan bahwa invasi pendidikan tinggi memasuki Indonesia akan berakibat buruk, apalagi bila tidak diatur untuk dapat memanfaatkan nilainilai positifnya dan menghindari nilai-nilai negatifnya.

Sementara menurut Azyumardi Azra, perguruan tinggi menghadapi berbagai dampak dari proses globalisasi dan liberalisasi. Pendanaan oleh pemerintah akan berkurang sehingga memaksa perguruan tinggi mengembangkan sumbersumber pendanaan sendiri. Di samping itu, kebutuhan bagi pengembangan program studi yang relevan dan dibutuhkan kemajuan globalisasi ilmu pengetahuan dan teknologi terus meningkat, dan lapangan kerja semakin berbasis ilmu pengetahuan (knowledge-based economy). Dampak lain adalah semakin mendominasi pengembangan bentuk-bentuk dalam merespon berbagai perkembangan. Sofian Effendi mengatakan implikasi jangka panjang, globalisasi pendidikan tinggi belum sepenuhnya dapat diperkirakan. Karena itu, kebijakankebijakan antisipatif perlu dirancang secermat mungkin agar globalisasi tidak sampai menghancurkan sektor pendidikan tinggi seperti yang terjadi dengan globalisasi sektor pertanian.

\section{Karakter dan Moral}

Proses pendidikan bukan hanya transfer pengetahuan, melainkan pembentukan watak dan moral. Dalam konteks Indonesia penyelenggaraan pendidkan tidak boleh mengabaikan watak dan moral yang berlandaskan nilai-nilai keindonesiaan, dan pendidikan tidak hanya ingin menghasilkananakdidtkyangmemilikketeramplan teknis dan profesional, tetapi juga anak didik yang berkembañ ḡebagaimanusiayangutundanmemiik tanggungjawabsosial.Pendidikan diharapkan dapat menjawab kebutuhan masyarakat dan bukan menjawab kebutuhan pasar semata. Pendidikan memperlakukan anak didiksebagai manusia dan bukan sebagai konsumen belaka.

Menurut Bernadette, liberalisasi pendidikan tinggi cenderung membuka akses bagipemilik modal besar untuk mendektekan kepentingan dan kebutuhannya kepada pendidikan tinggi berikut sumber dayanya. Al hasil, pendidikan tinggi bisa mengesampingkan pencarian kebenarañ dan upaya memanusiakan manusia secara utuh yang menjadi fungsi fundamental pendidikan, demi kepentingan industri bisnis yang mendanai. Masuknya kekuatan pasar, budaya korporasi, dan kekuatan industri akan mengarahkan misi 
pendidikan tinggi. Etika dan moral di dunia pendidikan tinggi dikuasai oleh etika dan moral bisnis yang berdasarkan mencari keuntungan dan efisiensi. Akuntabilitas pendidikan tinggi yang diagung-agungkan menjadi akuntabilitas dari pemegang modal. Masuknya lembaga pendidikan asing akan memicu peningkatan mutu pendidikan Indonesia, di samping itu akan meningkatkan akuntabilitas penyelenggaraan pendidikan, memperbaiki efisiensi pengelolaan pendidikan, dan mengurangi aliran uang ke luar negeri.

\section{Penutup}

Oleh karena globalisasi pendidikan tinggi menjadi konvensi WTO dan mendapat persetujuan dari kebanyakan anggotanya, terutama anggota dari negara-negara maju yang tentu saja lebih siap menjalankan praktik globalisasi itu sendiri, maka praktik globalisasi pendidikan tinggi akan sulit ditolak oleh negara-negara anggota, termasuk Indonesia. Terkecuali, anggotaanggota WTO itu sendiri bersepakat untuk tidak memasukkan pendidikan sebagai jasa yang dapat diperdagangkan atau dijual belikan.

Meskipun secara politis kita perlu memperhitungkan kapan waktu yang tepat untuk mengizinkan kehadiran PTAdi negara Indonesia, berapa jumlahnya, dari negara yang bagaimana, dengan kualifikasi seperti apa, dan sebagainya. Pada dasarnya kehadiran PTA memang tidak perlu ditolak. Kalau kita berpikir positif, hadirnya PTAjustru dapat dijadikan pemacu dan pemicu pengelola PTN dan PTS untuk meningkatkan mutu pendidikannya. Tanpa meningkatkan mutu, lembaganya tidak akan dilirik oleh masyarakat.

\section{Daftar pustaka}

Abel, Christopher, and Colin Lewis. 1993. Welfare, Poverty and Development in Latin America. London: Macmillan.

Barnet, Richard, and John Cavenagh. 1994. Global Dreams: Imperial Corporations and the New World Order. New York: Simon \& Schuster.

Bello, Walden. 1994. Dark Victory: United States, StructuralAdjusment and Global Powerty. London: Pluto Press.

Cammack, Paul. 1997. Capitalsm and Democrazy in the Third World. London: Leisister University.

Davis, Mike. 1984. The Political Economy of Late-Imperial America. New left Review 143 (Jan-Feb).

Diamond, L. 1992. Economic Development and Democrazy Reconsidered. American Behaqvioral Scientist 35 (4/5): 450.99 .

Meiksins Wood, Ellen. 1995. Democrazy Against Capitalism: Renewing Hostorical Materialism. Cambridge University Press.

Robinson, William. 1996. Globalization: Nine Theses on Epoch. Montelibre Mountly March/April.

UNDP. 1992. Human Development. Report 1992. New York: Oxford University Press.

Varman, Schneider, Benu..1991. Capital Flight From Developing Countries. Boulder. Colo: Westview Press. 